Int. J. Environ. Sci. Tech.

Vol. 2, No. 1, pp. 27-33, Spring 2005

\title{
Evaluation of advanced rice germplasm under water stress environment
}

\author{
"Y. Ali, G. Sarwar, Z. Aslam, F. Hussain and T. Rafique
}

Nuclear Institute for Agriculture and Biology, Faisalabad, Pakistan

\begin{abstract}
Thirteen genotypes of rice comprising of approved varieties and elite candidate lines were studied at three different water regimes by supplying 12, 8 and 4 numbers of irrigations at different intervals/ stages. The experiment was conducted at NIAB Farm Faisalabad, Pakistan on a clay loam soil applying normal doses of N and P fertilizers during 2002-2003 keeping varieties in the main plot while treatments in sub plot. The data for twelve morphological characters i.e. days to flower, days to mature, plant height, panicle length, number of productive tillers, number of primary and secondary branches, 1000 grain weight, sterile grains per spike, number of total grains per spike, fertility percentage, grain yield were recorded and subjected to analysis of variance and means were compared following DMR test. Effect of water stress on different morphological attributes in all treatments showed significant differences. Plant height, branches per plant, number of grains and grain yield reduced at less number of irrigations while sterility percentage was increased at less moisture conditions. Maximum grain yield (5349 Kg/ha) was achieved at T1 where 12 number of irrigations were applied at T2 (8 irrigations) and T3 (4 irrigations). The yield reduction was observed from $30.32 \%$ to $42.53 \%$, respectively as compared to T1 (12 irrigations). Rice variety DM 64198 produced the highest seed yield (4766 Kg/ha) followed by DM-3-89 (4770 Kg/ha).This might be due to different genetic make up of the breeding lines and their behavior and interaction in water stress environment. Furthermore, high irrigation level made possible the appropriate water availability possible at proper time for performing different types of physiochemical processes of development that hindered at less number of irrigation or water stress environment. It may be concluded that for achieving maximum economic yield, at least 12 irrigations were essential otherwise the production will be reduced to a considerable extent.
\end{abstract}

Key words: rice, genotype, water stress, germplasm

*Corresponding Author, E-mail: yousaf_sem@yahoo.com

\section{Introduction}

The main source of irrigation water in Pakistan is from vast canal system which is however, inadequate to meet crop water requirements and mainly supplemented with ground water (Ramzan, 2000). Water being the most scarce resource demands that it must be used most judiciously without wasting a single drop of it. Irrigation system of the Pakistan is the largest contiguous network of canals in the world. The irrigated area has considerably increased from 10 mha to 18 mha since 1960. A significant portion $\left(25 \%\right.$ or $\left.32 \mathrm{Bm}^{3}\right)$ of the diverted water is lost in the conveyance system. The losses in the field due to poor farm layouts, unleveled fields and wasteful irrigation practices are estimated as $45 \%$ or $43 \mathrm{Bm}^{3}$. Scarcities of water as droughts have the greatest adverse impact on the economy of the country. Furthermore the droughts affect large geographical areas and may last for months and in some cases extend over several years (Majeed, et al., 2002).The water availability situation in Pakistan has been seriously affected by extended droughts since 1999.
The production of rice decreased by $19 \%$ and reduced from 4803 thousand tonnes last year to 3882 thousand tonnes this year (Akram and Ashraf, 2002). Further the availability of water for agriculture, in particular for rice production, is threatened in many regions of the world (Wopereies, et al., 1994). The production of rice consumes much more water than that of other crops. Approximately, 500 liters water is needed to produce one kilogram of biomass in the case of irrigated rice (Jodo, 1995). However, actual water use or requirement for irrigation water was found to be far greater than this value for paddy rice (Seito and Shimoda, 1984; Tuong, et al., 1994 and Yoshida, 1981). Considering the scarcity of water, the economic management of water has become essential and attempts are underway to reduce huge volume of irrigation water required for rice crop production, intermittent irrigation for rice crop instead of flooding is aimed mainly at saving water. It has been reported that application of water 1-5 days after the disappearance of applied standing 
water saved $25-50 \%$ of irrigation water as compared to the continuous submergence of fields without any adverse affect on rice yield (Peng, et al., 1994 and Tajima, 1995).

In some under-saturated soil moisture conditions dry matter production and grain yield decreased significantly (Borrell, et al., 1997; Mishra, et al., 1997 and Jun Lu, et al., 2000). Keeping in view the shortage of water, the present research was planned to estimate the optimum water requirement of rice crop and the effect of water stress on production of its economical yield.

\section{Materials and Methods}

Thirteen genotypes of rice containing approved varieties and elite candidate lines of different research organizations were included in this experiment and are listed in Table 3. These genotypes were evaluated at three different water regimes i.e. 12 irrigations, 8 irrigations and 4 irrigations. At each time of irrigation, the field was flooded with canal water up to three inches depth approximately. The experiment was conducted on clay loam soil of NIAB Farm at Faisalabad, applying normal doses of $\mathrm{N}$ and $\mathrm{P}$ fertilizer in $24 \mathrm{~m}^{2}$ plots during 2002-2003 with three repeats keeping varieties in the main plots and treatment in the subplots.

Twelve morphological characteristics i.e. days to flower, days to mature, plant height, panicle length, number of productive tillers, number of primary branches, number of secondary branches, 1000 grain weight, sterile grains per spike, number of total grains per spike, fertility percentage, yield per plant, yield $\mathrm{Kg} / \mathrm{ha}$ were recorded on plant and plot basis and the data thus collected were subjected to analysis of variance and means were compared following DMR test (Steel and Torrie, 1980).

\section{Results}

Analysis of variance of grain yield of rice varieties at different treatments of irrigation showed that varieties and irrigation treatments, and varieties $\mathrm{x}$ irrigation interaction exhibited highly significant differences (Table 1).

Effect of water stress on different morphological attributes indicated that all treatments showed significant differences. Plant height $(117.4 \mathrm{~cm}$.), panicle length $(26.7 \mathrm{~cm}$.), number of productive tillers (16.0), number of primary branches (8.7), number of secondary branches (23.8), 100 grain weight (23.5) number of total grains per spike (146.2), fertility percentage, yield per plant (36.8) and grain yield/plot (5349 Kg ha-1) showed the highest values at maximum level of irrigation (T1) while lowest values were observed at T3 (4 irrigations). The sterile grains per spike (18.1) were less at T3 as compared to T2 (28.1) and T1 (24.6). The pattern of behavior was of similar nature in all the rice genotypes under study.

The genotype DM-3-89 gained significantly (Table 3) the highest plant height $(143 \mathrm{~cm}$.) followed by Jhona-349 x Bas $370(140 \mathrm{~cm}$.) and Jhona 349 (131 cm.). The lowest plant height was observed in genotype DM 38/88 (71 cm.).

Maximum days to flowering were noted in genotype DM-38/88 (118d) and minimum in genotype DM-63275 (105d). Genotype DM-3-89 attained maximum panicle length $(31 \mathrm{~cm}$.) while genotype Jhona349 x BAS-370 produced the lowest panicle length $(21 \mathrm{~cm}$.). Productive tillers were highest (19) in genotype DM 64198 and lowest (12) in genotype NIAB 6 x DM 25, Jhona 349 x Bas 370, DM 5-89 and DM 63275.

Primary branches were maximum in genotype DM 38/88 (10) and minimum (16) in Basmati $370 \mathrm{x}$ NR-1 (7) while secondary branches were highest in genotype DM 63275 (29) and lowest (16) in Bas $370 \times$ NR-1 and Jhona $349 \times$ Bas 370. Thousand grain weight was maximum (25 g) in genotype NR1 and DM 63275 and minimum in DM 25 x NIAB 6 (16 g). NR-1 showed maximum no. of sterile grains (43) and lowest in DM 64198 (18). Total no. of grains per spike were highest in genotype DM 63275 (167) and lowest in Bas 370 x NR-1 (103).

Fertility percentage of grains was higher in genotype DM 64198 (84\%) and lowest in genotype Bas 370 x NR-1 (57\%). Grain yield per plant was highest in DM 64198 (42 g) and lowest in Jhona 349 x Bas 370 (16). Genotype DM 64198 produced significantly the higher grain yield $\left(4766 \mathrm{Kg} \mathrm{ha}^{-1}\right)$, followed by Jhona 349 x Bas 370 (4464 Kg ha ${ }^{-1}$ ).the lowest grain yield (2833 Kg ha-1) was produced by genotype DM-5-89.

While studying paddy rice Jun Lu, et al., 2000 also observed reduction in the dry matter production and grain yield in the intermittent irrigation while be stated was might be due to reduction in growth rate resulted from decrease in the net assimilation rate due to non availability of appropriate water quantity at proper time.

Some other repots also mentioned the decrease in dry matter production and grain yield under unsaturated soil moisture conditions (Borrell, et al., 1997). 

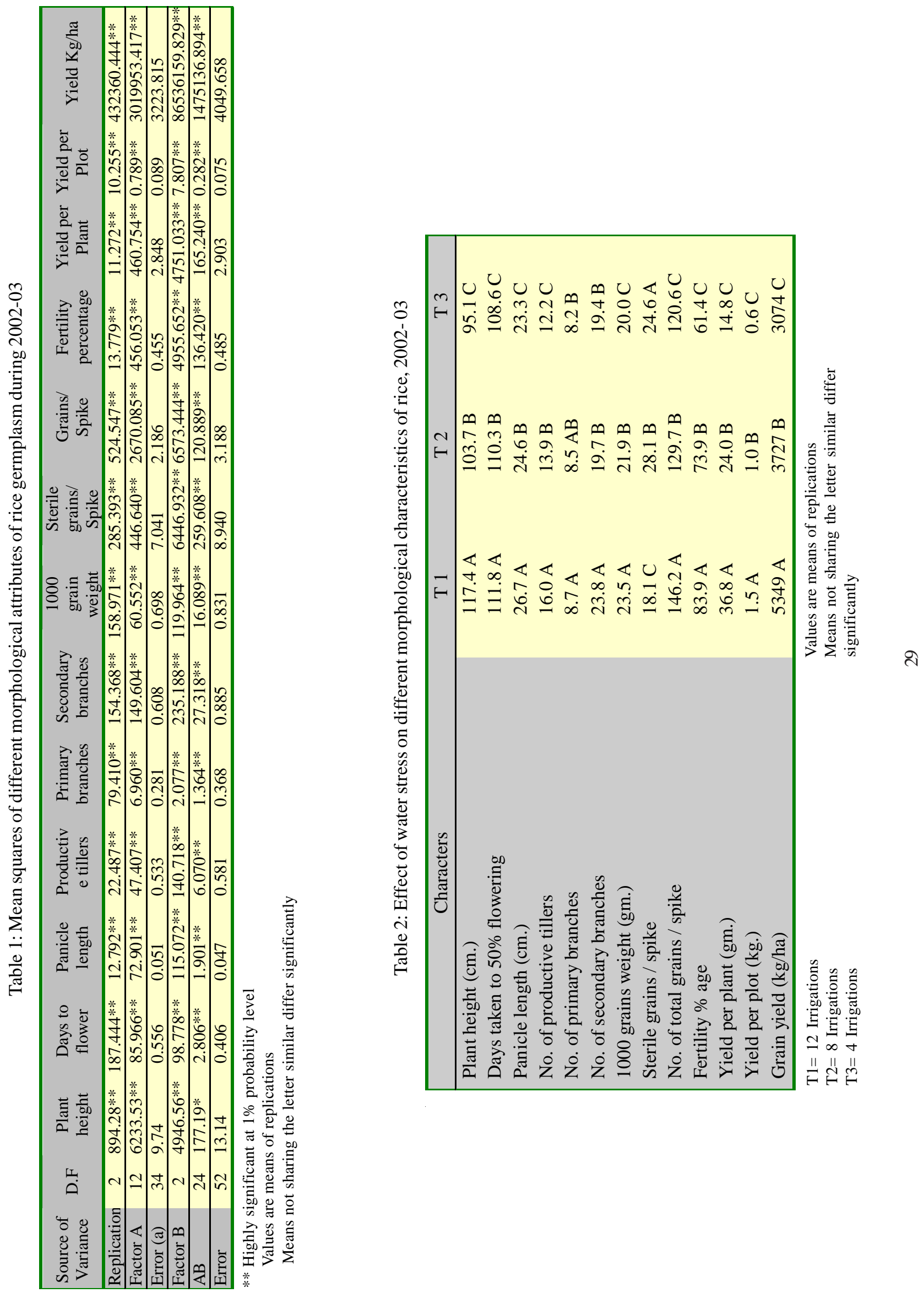


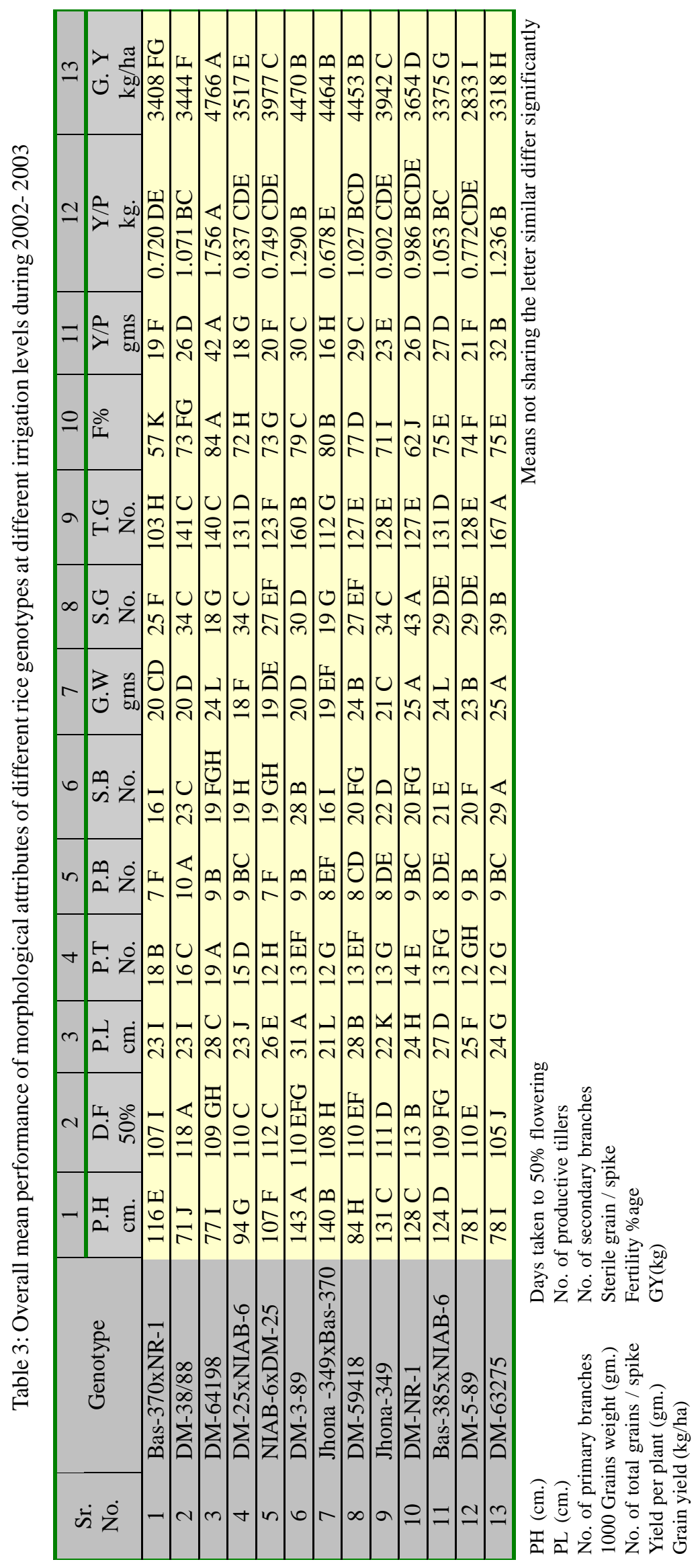



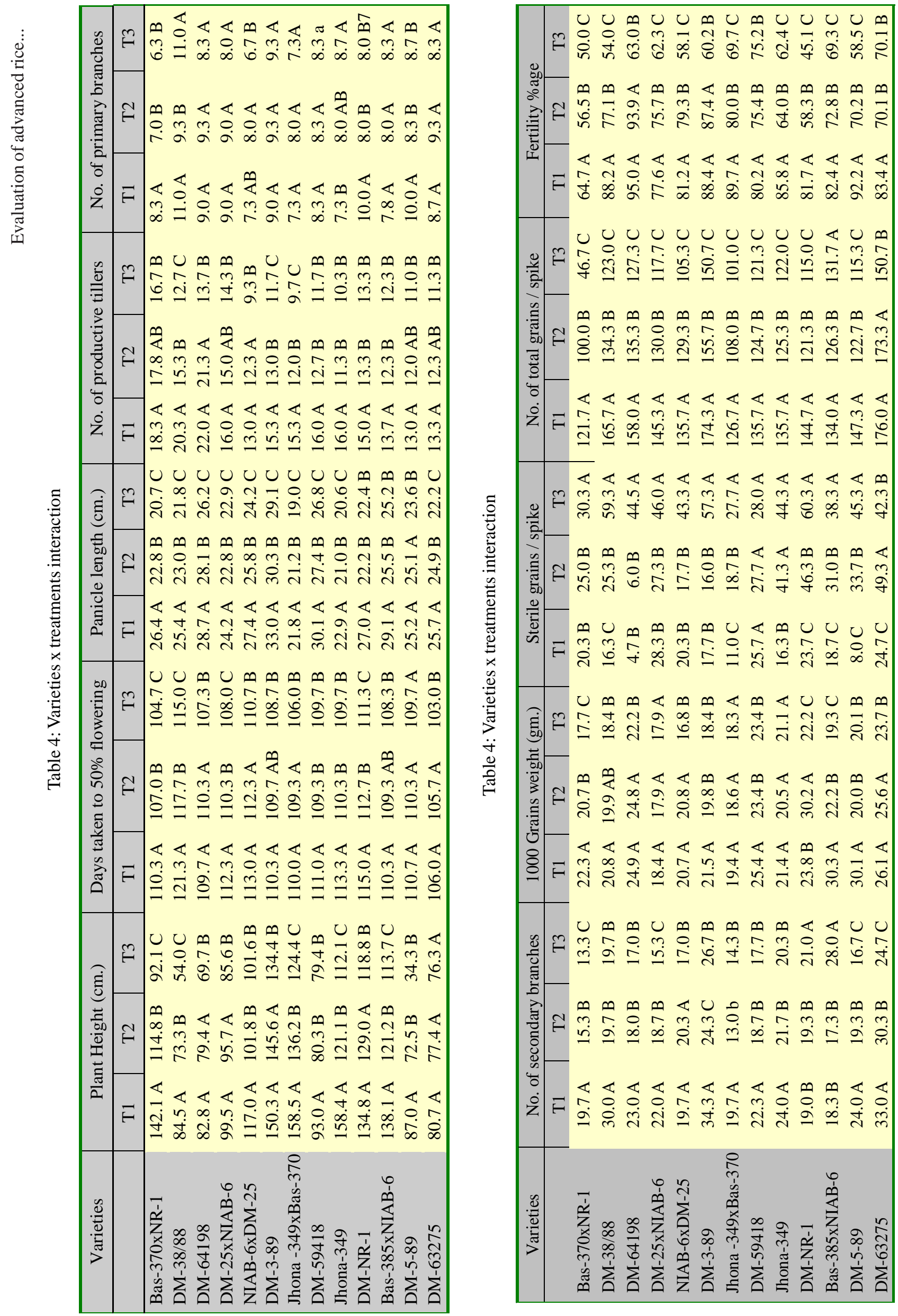
Table 4: Varieties x treatments interaction

\begin{tabular}{|c|c|c|c|c|c|c|c|c|c|}
\hline \multirow[t]{2}{*}{ Varieties } & \multicolumn{3}{|c|}{ Yield per plant (gm) } & \multicolumn{3}{|c|}{ Yield per plot (kg) } & \multicolumn{3}{|c|}{ Grain yield (kg/ha) } \\
\hline & T1 & T2 & T3 & T1 & $\mathrm{T} 2$ & T3 & $\mathrm{T} 1$ & $\mathrm{~T} 2$ & T3 \\
\hline Bas-370xNR-1 & $34.5 \mathrm{~A}$ & $18.2 \mathrm{~B}$ & $5.1 \mathrm{C}$ & $1.2 \mathrm{~A}$ & $0.7 \mathrm{~B}$ & $0.2 \mathrm{C}$ & $5564 \mathrm{~A}$ & 3944 B & $716 \mathrm{C}$ \\
\hline DM-38/88 & $52.4 \mathrm{~A}$ & 17.3 B & $8.2 \mathrm{C}$ & $2.3 \mathrm{~A}$ & $0.6 \mathrm{~B}$ & $0.3 \mathrm{~B}$ & $5863 \mathrm{~A}$ & 3683 B & $786 \mathrm{C}$ \\
\hline DM-64198 & $65.0 \mathrm{~A}$ & $47.4 \mathrm{~B}$ & $14.7 \mathrm{C}$ & $2.6 \mathrm{~A}$ & $1.8 \mathrm{~B}$ & $0.9 \mathrm{C}$ & $5973 \mathrm{~A}$ & $4480 \mathrm{~B}$ & $3843 \mathrm{C}$ \\
\hline DM-25xNIAB-6 & $25.2 \mathrm{~A}$ & 17.6 B & $9.7 \mathrm{C}$ & $1.3 \mathrm{~A}$ & $0.8 \mathrm{~B}$ & $0.5 \mathrm{~B}$ & $5634 \mathrm{~A}$ & 3566 B & $1351 \mathrm{C}$ \\
\hline NIAB-6xDM-25 & $25.9 \mathrm{~A}$ & $23.2 \mathrm{~A}$ & $11.5 \mathrm{~B}$ & $1.0 \mathrm{~A}$ & $0.7 \mathrm{~A}$ & $0.05 \mathrm{~A}$ & $5429 \mathrm{~A}$ & 3656 B & $2845 \mathrm{C}$ \\
\hline DM-3-89 & $39.2 \mathrm{~A}$ & $33.1 \mathrm{~B}$ & $16.9 \mathrm{C}$ & $1.7 \mathrm{~A}$ & $1.3 \mathrm{AB}$ & $0.9 \mathrm{~B}$ & $5802 \mathrm{~A}$ & $4225 \mathrm{~B}$ & $3381 \mathrm{C}$ \\
\hline Jhona-349xBas-370 & $24.3 \mathrm{~A}$ & $13.8 \mathrm{~B}$ & $9.0 \mathrm{C}$ & $1.1 \mathrm{~A}$ & $0.6 \mathrm{~B}$ & $0.4 \mathrm{~B}$ & $5486 \mathrm{~A}$ & $4227 \mathrm{~B}$ & $3678 \mathrm{C}$ \\
\hline DM-59418 & $31.2 \mathrm{~A}$ & $30.2 \mathrm{~A}$ & $25.6 \mathrm{~B}$ & $1.1 \mathrm{~A}$ & $1.0 \mathrm{~A}$ & $1.0 \mathrm{~A}$ & $4859 \mathrm{~A}$ & $4438 \mathrm{~B}$ & $4060 \mathrm{C}$ \\
\hline Jhona-349 & $40.7 \mathrm{~A}$ & $15.1 \mathrm{~B}$ & $11.7 \mathrm{C}$ & $1.7 \mathrm{~A}$ & $0.5 \mathrm{~B}$ & $0.5 \mathrm{~B}$ & $5169 \mathrm{~A}$ & 3591 B & $3066 \mathrm{C}$ \\
\hline DM-NR-1 & $31.4 \mathrm{~A}$ & $25.0 \mathrm{~B}$ & $22.1 \mathrm{C}$ & $1.2 \mathrm{~A}$ & $1.0 \mathrm{AB}$ & $0.7 \mathrm{~B}$ & $5398 \mathrm{~A}$ & 3305 B & $2260 \mathrm{C}$ \\
\hline Bas-385xNIAB-6 & $36.0 \mathrm{~A}$ & $24.4 \mathrm{~B}$ & $19.8 \mathrm{C}$ & $1.2 \mathrm{~A}$ & $1.3 \mathrm{~A}$ & $0.7 \mathrm{~B}$ & $5006 \mathrm{~A}$ & 3336 B & $1780 \mathrm{C}$ \\
\hline DM-5-89 & $31.2 \mathrm{~A}$ & $16.1 \mathrm{~B}$ & $15.0 \mathrm{~B}$ & $1.2 \mathrm{~A}$ & $0.6 \mathrm{~B}$ & $0.5 \mathrm{~B}$ & $3683 \mathrm{~A}$ & 3113 B & $1701 \mathrm{C}$ \\
\hline DM-63275 & $41.5 \mathrm{~A}$ & $30.5 \mathrm{~B}$ & $23.8 \mathrm{C}$ & $1.7 \mathrm{~A}$ & $1.3 \mathrm{~A}$ & $0.7 \mathrm{~B}$ & $5671 \mathrm{~A}$ & 2886 B & $1394 \mathrm{C}$ \\
\hline
\end{tabular}

Values are means of replications

Means not sharing the letter similar differ significantly

Regarding interaction between varieties $\mathrm{x}$ treatments (Table 4), the variety Basmati x NR-1 attained maximum plant height $(142.1 \mathrm{~cm}$.) in $\mathrm{T} 1$. Days to $50 \%$ flowering (115) were maximum in variety NR-1 in T1, panicle length $(33 \mathrm{~cm})$ in variety DM-3-89 in T1. No. of productive tillers were highest $(22 \mathrm{~cm}$.) in T1 of variety DM 64198. Primary branches were maximum (11) in DM 38/88 in T1 and T3 and secondary branches in variety DM 63275 (33) in treatment T1. One thousand grain was highest in T2 of variety NR-1 (30.2) and sterile grains per spike in T3 in variety DM 38/88 (59). No. of total grains per spike were maximum in DM 63275 (176) in T1 and fertility percentage was highest (95\%) in variety DM 64198 in T1. Grain yield per plant was maximum in variety DM 64198 (65 g) in $\mathrm{T} 1$ and grain yield per plant was highest in variety DM 64198 (5973 kg/ha) in T1. Studying Aman rice in Bangladesh, Rehman, et al., 2002 also observed similar kind of results. Among the four irrigations of rice they noted that Bangladesh produced highest seed yield. As compared to this Bangladesh showed the highest Total Dry Matter (TDM) and plant height. But it produced lower grain yield under stress conditions.

\section{Discussion and Conclusion}

Reduction to water stress was observed in all the yield components i.e. plant height, panicle length, no. of productive tillers, branches per plant and 100seed-weight (Table 2). The seed yield it ultimately reduced due to stress effect on yield components. The sterility was more pronounced in less irrigation treatments as compared to T1 where maximum numbers of irrigations were applied. This was vice versa when compared to fertility percentage. The reduction in yield was $30.32 \%$ to $42.53 \%$ in case of $\mathrm{T} 2$ and T3, respectively as compared to T1. This might be due to reduction in growth rate resulting from decrease in the net assimilation rate due to non-availability of appropriate water quantity at proper time.

Significant difference in all morphological attributes including seed yield were observed in all the rice genotypes under study. This might be due to different genetic make up of the genotypes and their behavior and interaction in stress environment. The maximum seed yield ( $4766 \mathrm{~kg} / \mathrm{ha}$ ) was produced by DM 64198 followed by DM-3-89 (4770 kg/ha). In case of varieties $\mathrm{x}$ treatment interaction the highest grain yield (5973 kg/ha) was achieved in T1 by variety DM 64198. This might be on account of water availability at proper time for performing different types of physiological and physiochemical process of development that were hindered in other treatments where less number of irrigations were applied to create water stress.

From the results of this research work, it may be concluded that for achieving maximum economic yield, at least 12 irrigations are essential, otherwise yield would be reduced to a maximum extent.

\section{References}

Borrell, A., A. Garside. and S. Fukai, Improving efficiency of water use for irrigated rice in a semi-arid tropical environment. Field Crops Res., 52: 231-248, 1997 
Castillo, E. G., R. J. Buresh and K. T. Ingram, Lowland rice yield as affected by timing of water deficit and nitrogen fertigation. Agron. Journal, 84: 152-159, 1992

Jodo, S., Water use efficiency. In: Science of the Rice Plant. 2. Physiology, T. Matsuo, K. Kumazawa, R. Ishii, K. Ishihara and H. Hirate. (eds). Food and Agriculture Policy Research Center, Tokyo, 461-47, 1995

Jun, Lu, T. Dokawa and T. Hirasawa, The effects of irrigation regimes on the water use, dry matter production and physiological responses of paddy rice. Plant and Soil. 223: 207-216, 2000.

Kahlown, M. A. and M. Ashraf, Water management strategies under drought conditions. In: M. A. Kahlown, N. Yasmin and M. Ashraf (eds.) Proceedings of the SAARC workshop on "Drought and water management strategies," Lahore, Pakistan, 47-59, 2002

Ramzan, M. C., Ground water quality variation in Pak. Proceedings of Seminar on Regional Ground water, held at Islamabad, 9-11, 2000

Majeed, A., M. Azam and A. Mumtaz, Drought and water management strategies in Pakistan. In: M.A. Kahlown, $N$. Yasmin and M. Ashraf (eds.) Proceedings of the SAARC workshop on "Drought and water management strategies,” Lahore, Pakistan, 119-135, 2002

Mishra, H.S, T. R. Rathore and R. C. Pant, Root growth, water potential and yield of irrigated rice. Irrig. Sci. 17: 69-75, 1997
Peng, S. Z., S. S. Li., G. I Xu and Z. J. Wn, New water consumption pattern of rice under water saving irrigation. Irrigation and Drainage. 8: 97-108, 1994

Rehman, M. T., M. T. Islam and M. O. Islam, Effect of water stress at different growth stages on yield and yield contributing characters of transplanted Aman rice. Pak. J. Bio. Sci., 5(2): 169-172, 2002

Saito, K. and H. Shimadu, A case study on irrigation water requirement in University Farm. Bull. Farms Tokyo Uni. Agri. Tech. 11: 31-40, 1984

Steel, R. G. D. and T. H. Torrie, Principles and procedures of statistics. $2^{\text {nd. }}$ Ed., Mc Graw Hill Book Co. Inc. New York, 481, 1980

Tajime, K., Occurrence and mechanism of drought change. In: Science of the Rice Plant.2. Physiology. T. Matsuo, K. Kumazawa, R. Ishii, K. Ishihara and H. Hirate. (eds) Food and Agriculture Policy Research Center, Tokyo. pp. 838-849, 1995

Tung, T. R. P., M. C. S. Wopereis., J. A. Marquez and M. J. Kropff, Mechanism and control of percolation losses in irrigation puddled rice fields. Soil. Sci. Soc. Am. J., 58: 1794-1803, 1994

Woperiesies, M. C. S., B. A. M. Bouman, M. J. Kropff, H. F. M. Ten Berge and T. P. Tuong. Water use efficiency of flooded rice fields. Validation of soil water balance model SAWAH. Agri. Water Manage., 26: 277-289, 1994

Yoshida, S., Fundamentals of rice crop sciences. International Rice Research Institute, Los Banas, Philippines. 269, 1981 